\title{
STRATEGI PENGEMBANGAN USAHA KOPI ORGANIK PADA KELOMPOK USAHA BERSAMA (KUB) MANDIRI SEJAHTERA NGRANCAH GRABAG KABUPATEN MAGELANG
}

\author{
Strategy For The Development Of Organic Coffee Business In Kelompok Usaha \\ Bersama (KUB) Mandiri Sejahtera Ngrancah Grabag Kabupaten Magelang
}

\author{
Afionita Rizki Pratiwi, Dwi Aulia Puspitaningrum, Indah Widowati \\ Program Studi Agribisnis Jurusan Agribisnis Fakultas Pertanian Universitas \\ pembangunan nasional Veteran Yogyakarta \\ Jl. SWK 104 (Lingkar Utara) Condongcatur Yogyakarta Indonesia 55283 \\ *Email korespondensi : afionitarp19@gmail.com
}

Diterima tanggal : 30 September 2020 ; Disetujui tanggal : 7 Oktober 2020

\begin{abstract}
This research was done carried out in the Kelompok Usaha Bersama (KUB) Mandiri Sejahtera organic coffee business in Desa Ngrancah, Kecamatan Grabag , Kabupaten Magelang . KUB Mandiri Sejahtera has strenght, weakness, opportunity, threet to formulate strategies to develop their business The purpose of this study was, strategies analyze for get solution in KUB Mandiri Sejahtera. The research method was descriptive model. The type of research was a case study in KUB Mandiri Sejahtera which was the one only organic coffee business in the Grabag Subdistrict Magelang district. The method of respondents had taken by purposive method. The type data was primary and secondary data. The sources of Primary data were interview result, secondary data source were collectif data . The method of collecting data was interview, observation, record. Techniques analysis to analyze a businees development strategy with IFE (Internal Factor Evaluation), EFE (Exsternal Factor Evaluation), matrix IE (Internal Exsternal), SWOT strength, weakneses,opportuniti,threat), and with QSPM (Quantitative Strategic Planning Matrix) model. Based on the research that had been done, the result of the research showed that The solution of the strategy of KUB Mandiri Sejahtera to improve the organic coffee product can be develop by market expanding of sales area. For that it was necessary to improve the management system and also increase sales by using social media and also e-commerce
\end{abstract}

Keywords: Coffee, Strategy, SWOT, QSPM

\begin{abstract}
ABSTRAK
Penelitian ini dilakukan di usaha kopi Kelompok Usaha Bersama (KUB) Mandiri Sejahtera di Desa Ngrancah Kecamatan Grabag Kabupaten Magelang. KUB Mandiri Sejahtera di dalam usahanya memiliki kekuatan, kelemahan, peluang dan ancaman yang dapat digunakan untuk merumuskan sebuah strategi untuk mengembangkan usahanya. Tujuan penelitian ini adalah Menganalisis strategi pengembangan usaha di KUB Mandiri Sejahtera. Metode penelitian dengan metode deskriptif, metode pelaksanaan studi kasus yaitu kopi ngrancah
\end{abstract}


merupakan satu-satunya kopi organik di Kecamatan Grabag, metode pengambilan responden metode purposive sampling dengan mengambil 8 orang dari pihak KUB Mandiri Sejahtera, jenis data adalah data primer dan data sekunder, sumber data primer yaitu hasil wawancara, sumber data skunder yaitu studi pustaka serta metode pengambilan data wawancara, observasi, dan pencatatan . Teknik analisis data secara EFI (Evaluasi Faktor Internal), EFE (Evaluasi Faktor Eksternal), matriks IE (Internal Eksternal), SWOT (strength, weakneses,opportuniti,threat), dengan alat analisis QSPM (Quantitative Strategic Planning Matriks). Berdasarkan penelitian yang telah dilakukan didapatkan hasil penelitian Strategi pengembangan usaha yang dapat dilakukan adalah melakukan pengembangan pasar dengan memperluas wilayah penjualan produk kopi KUB Mandiri Sejahtera. Untuk itu perlu dilakukan perbaikan pada sistem manajemen dan juga lebih meningkatkan penjualan dengan menggunakan media sosial dan juga e-commerce

Kata kunci : Kopi, Strategi , SWOT, QSPM

\section{PENDAHULUAN}

Desa Ngrancah merupakan sebuah desa yang terletak di Kecamatan Grabag, Kabupaten Magelang. Luas perkebunan kopi di desa ini kurang lebih sekitar 100 hektar (Pertiwi,2018). Banyaknya petani kopi dan perkebunan kopi yang ada di Desa Ngrancah maka dibentuklah suatu kelompok usaha bersama yang diberi nama KUB Mandiri Sejahtera. Kelompok Usaha Bersama yaitu salah satu program pemerintah yang ada pada Kementerian Sosial RI khususnya di Direktorat Jenderal Pemberdayaan Sosial dan Penanggulangan Kemiskinan yang bertujuan untuk memberdayakan kelompok masyarakat miskin dengan pemberian modal usaha melalui program Bantuan Langsung Pemberdayaan Sosial (BLPS) untuk mengelola Usaha Ekonomi Produktif (UEP) (Susanto, 2019)

Produk yang terkenal dari Desa Ngrancah ini adalah kopi bubuk. Kopi yang ditanam di desa ini merupakan kopi jenis robusta yang ditanam secara organik. Dalam melakukan usahanya KUB Mandiri Sejahtera tentu memiliki sebuah kekuatan dalam usahanya seperti produk kopi merupakan kopi organik dengan harga yang terjangkau. Kelemahan dalam usahanya seperti dalam manajemen pembukuan masih sederhana dilihat dari pencatatan ini hanya sekedar catatan yang tidak tertata dengan rapi dan terkadang tidak tercatat secara detail. Ancaman dari luar usahanya yaitu mulai tumbuh usaha kopi di daerah-daerah kawasan Kabupaten Magelang, serta selera konsumen kopi. Peluang untuk memajukan usahanya seperti produk kopi sangat banyak diminati dan menjadi 
Pratiwi et.al. Analisis Kelayakan dan Strategi Pengembangan Usaha Kopi di KUB..

salah satu favorit minuman. Dari kekuatan, kelemahan, ancaman, dan juga peluang yang ada maka pihak KUB Mandiri Sejahtera tentu dapat melakukan sebuah strategi yang bertujuan untuk meningkatkan usaha kopi.

Manajemen strategi (strategic management) menurut Hunger J David \& Thomas L Wheelen dalam bukunya berjudul Manajemen Strategis hasil alih bahasa oleh Julianto Agung dalam Juwono, (2011) adalah serangkaian keputusan dan tindakan manajerial yang menentukan kinerja perusahaan dalam jangka panjang. Strategi sebagai suatu alat untuk mencapai tujuan jangka panjang. Selain itu strategi juga diartikan sebagai tindakan potensial yang membutuhkan keputusan manajemen tingkat atas dan sumber daya perusahaan dalam jumlah yang besar (Alyas et all, 2017) Proses manajemen strategi adalah alur dimana penyusun strategi akan menentukan sasaran dan menyusun keputusan strategi. Menurut David (2002), proses manajemen strategis terdiri dari tiga tahap yaitu tahap perumusan strategi, implementasi strategi dan evaluasi strategi. pada prinsipnya strategi dapat dikelompokkan berdasarkan 3 tipe strategi yaitu strategi manajemen, strategi investasi, strategi bisnis (Rosyadi, 2013).Berdasarkan latar belakang tersebut penelitian ini bertujuan untuk menganalisis strategi pengembangan usaha kopi organik di KUB Mandiri Sejahtera

\section{METODE PENELITIAN}

Penelitian ini menggunakan pendekatan deskriptif yang dilakukan di usaha kopi organik KUB Mandiri Sejahtera. Metode pelaksanaan penelitian menggunakan studi kasus dengan subjek penelitian Penelitian ini dilakukan karena satu-satunya usaha di Kecamatan Grabag yang bergerak pada pengolahan kopi yang telah bersertifikat organik. Metode pengambilan responden yang digunakan adalah secara purposive yaitu mengambil responden secara sengaja (Nazir, 1983) dengan 8 orang dari KUB Mandiri Sejahtera yang mengerti tentang KUB. Jenis data yang digunakan merupakan kuantitatif dengan sumber data yaitu data primer yang didapat dari hasil wawancara dan data skunder yang berdasarkan dokumen yang dimiliki. Kemudian data yang didapat untuk melakukan strategi pengembangan usaha akan dilakukan analisis yang pertama yaitu dengan matriks 
Jurnal Dinamika Sosisal Ekonomi, 21 (2) : 190-204

EFI dan EFE, pencocokan dengan matriks IE, kemudian SWOT, dan keputusan menggunakan matriks QSPM.

\section{HASIL DAN PEMBAHASAN}

Pada analisis strategi pengembangan usaha yang dilakukan pertama tama adalah melakukan terlebih dahulu identifikasi factor internal dan juga factor eksternal. Analisis lingkungan internal dan eksternal dilakukan dengan cara pemberian bobot pada masing-masing variabel internal dan eksternal berdasarkan tingkat kepentingan menggunakan skala likert (Effendi et all, 2017). Identifikasi factor internal ini sendiri dimulai dengan mendata kekuatan yang dimiliki dan juga kelemhan yang dimiliki. Kemudian untuk factor eksternal adalah dengan mendata peluang dan juga ancaman yang dimiliki. Selanjutnya adalah memberikan bobot, rating dan skor pada factor internal dan factor eksternal. Skor pada masing-masing factor internal dan juga eksternal kemudian digunakan untuk melihat pada matrik internal eksternal (IE) untuk mengetahui usaha ini berada di posisi seperti apa. Matriks IE adalah suatu matriks yang digunakan untuk mengetahui posisi suatu perusahaan. Matriks IE didasarkan pada total nilai Matriks IFE yang diberi bobot pada sumbu $X$ dan total nilai Matriks EFE yang diberi bobot pada sumbu Y (Effendi et all, 2017).

Pencocockan selanjutnya adalah menggunakan matrik SWOT dimana matriks ini digunakan untuk merumuskan strategi dengan memanfaatkan kekuatan dan peluang, serta meminimalkan kelemahan dan juga ancaman. Di dalam analisis SWOT terdapat startegi SO, WO, ST, WT yang mana masing-masing strategi diberikan skor dengan melihat skor dari matriks EFI dan EFE. Maka akan dilihat skor tertinggi pada strategi apa. Pada tahap keputusan menggunakan matriks QSPM, matriks ini menggunakan patokan 2 strategi yang telah disesuaikan dengan hasil matrik IE usaha ini terdapat pada sel nomer berapa. Kemudian dilakukan penskoran dengan menggunakan skor hasil EFI dan EFE dan juga hasil dari nilai attractive scor. 
Pratiwi et.al. Analisis Kelayakan dan Strategi Pengembangan Usaha Kopi di KUB..

\section{Analisis lingkungan Internal}

Analisis lingkungan internal terdapat kekuatan dan juga kelemahan. Pada kekuatan yang dimiliki oleh KUB Mandiri Sejahtera ini sendiri terdapat di dua aspek, yaitu pemasaran dan produksi dan oprasi. Sedangkan untuk kelemahan berasal dari aspek manajemen, produksi dan oprasi, keuangan, dan SDM (David 2002)

Pada kekuatan yang dimiliki oleh KUB Mandiri Sejahtera ini sendiri terdapat di dua aspek, yaitu pemasaran dan produksi dan oprasi. Aspek pemasaran memiliki kekuatan harga kopi yang terjangkau, hal ini terlihat dari harga kopi ngrancah sebesar Rp. 25.000 dengan isi per kemasannya 150 gram dan kualitas kopi organik serta asli murni. Kemudian produk kopi ini organik, hal ini memang menjadi keunggulan dari produk kopi ngrancah, hal ini terbukti dari pihak KUB Mandiri Sejahtera memberikan ketentuan penanaman pada para anggota petani secara organik sehingga bahan baku yang digunakan adalah kopi yang organik dan yang lebih meyakinkan adalah telah memiliki sertifikat organik. Kualitas produk kopi ini baik, dikarenakan memiliki rasa kopi yang enak dan produk ini halal. Selain kualitasnya baik, produk ini juga memiliki rasa yang khas, yaitu rasa manis, kecut, masam, dan rasa ini diperoleh karena faktor alam dimana Desa Ngrancah ini berada di ketinggian dan rasa manis di dapat karena kebun kopi yang ada di Desa Ngrancah dipercaya karena bersebelahan dengan tanaman aren. Sedangkan dari aspek produksi dan oprasi memiliki kekuatan mudah mendapatkan bahan baku hal ini dikarenakan di Desa Ngrancah ini memiliki perkebunan kopi yang luas sehingga pihak KUB akan mudah mendapatkan bahan baku. . Kemudian adanya produksi yang berkelanjutan, walaupun dalam melakukan produksi masih belum ada kejelasan waktu namun produksi ini akan tetap berlanjut. Bahan baku merupakan kopi organik hal ini dapat dilihat dari pihak KUB Mandiri Sejahtera hanya mau membeli bahan baku dari petani yang sudah melakukan prosedur menanam dan perawatan kopi secara organik. Dari Evaluasi faktor internal untuk kekuatan yang dimiliki pihak KUB Mandiri Sejahtera didapatkan nilai skor sebesar 3,55. 
Kelemahan yang dimiliki oleh pihak KUB mandiri Sejahtera ini berasal dari aspek manajemen, produksi dan oprasi, keuangan, dan SDM. Dalam aspek manajemen yang sangat menonjol adalah permasalahan memanage masalah keuangan yaitu sistem pembukuannya yang masih sederhana yang hanya dicatat di dalam buku kecil tanpa ada perhitungan masalah keuntungan dan tidak selalu dilakukan pencatatan uang masuk dan uang keluar. Kelemahan pada produksi dan oprasi adalah masalah teknologi yang digunakan, hal ini dikarenakan peralatan yang dimiliki oleh KUB Mandiri Sejahtera ini adalah alat-alat yang belum terbarukan sehingga secara kuantitas terbatas. Untuk keuangan sendiri adalah keterbatasan dari modal itu sendiri, hal ini karena pihak KUB Mandiri Sejahtera selama ini mendapatkan bantuan dari pemerintah atau dari pihak swasta sehingga jika ingin mengembangkan usahanya menurut mereka agak sulit. Secara SDM, dikarenakan sebelum adanya bantuan peralatan kopi sudah terbiasa dengan pembuatan kopi tradisional, sehingga hal ini membuat yang memahami akan pembuatan kopi secara modern adalah kalangan anggota yang masih muda dan mau aktif saja. Dari evaluasi faktor internal pada kelemahan memiliki skor 0,3. Sehingga jika skor kekuatan dan kelemahan di jumlahkan akan mendapatkan nilai total skor untuk evaluasi faktor internal sebesar 3,85.

Tabel 1.Hasil Matriks EFI (Evaluasi Faktor Internal) KUB Mandiri Sejahtera Tahun 2020

\begin{tabular}{lccc}
\hline & Bobot (a) & Rating (b) & $\begin{array}{c}\text { Skor } \\
\text { (a x b) }\end{array}$ \\
\hline \multicolumn{1}{c}{ Kekuatan } & & & \\
Harga produk terjangkau & 0,12 & 3,87 & 0,46 \\
Produk kopi organik & 0,09 & 3,62 & 0,32 \\
Kualitas produk baik & 0,12 & 3,75 & 0,45 \\
Memiliki produk yang khas & 0,12 & 3,75 & 0,45 \\
Mudah mendapatkan bahan baku & 0,12 & 4 & 0,48 \\
Produksi yang berkelanjutan & 0,09 & 3,75 & 0,34 \\
Bahan baku merupakan kopi organik & 0,09 & 3,50 & 0,31 \\
\hline \multicolumn{1}{c}{ Jumlah } & $\mathbf{0 , 7 3}$ & $\mathbf{2 6 , 2 5}$ & $\mathbf{3 , 2 5}$ \\
\hline
\end{tabular}


Pratiwi et.al. Analisis Kelayakan dan Strategi Pengembangan Usaha Kopi di KUB..

Tabel 1. Lanjutan Hasil Matriks EFI (Evaluasi Faktor Internal) KUB Mandiri Sejahtera Tahun 2020

\begin{tabular}{|c|c|c|c|}
\hline & Bobot (a) & Rating (b) & $\begin{array}{c}\text { Skor } \\
(\mathbf{a} \times \mathbf{b})\end{array}$ \\
\hline \multicolumn{4}{|l|}{ Kelemahan } \\
\hline Sistem pembukuan sederhana & 0,06 & 1,62 & 0,09 \\
\hline Teknologi peralatan kurang & 0,03 & 1,87 & 0,05 \\
\hline Memiliki keterbatasan modal & 0,03 & 1,37 & 0,04 \\
\hline $\begin{array}{l}\text { Hanya anggota yang usia muda yang } \\
\text { menguasai pengolahan kopi secara } \\
\text { modern }\end{array}$ & 0,06 & 2 & 0,12 \\
\hline Jumlah & $\mathbf{0 , 1 8}$ & 6,87 & $\mathbf{0 , 3}$ \\
\hline Total & 1,00 & 33,12 & 3,55 \\
\hline
\end{tabular}

Sumber : Analisis data primer 2020

Berdasarkan matriks EFI, total skor sebesar 3,55 yang berarti lebih besar dari 2,5. Hal tersebut menunjukkan bahwa usaha kopi di KUB Mandiri Sejahtera dalam menghadapi dinamika lingkungan internal posisi perusahaan relatif kuat (David, 2002). Kekuatan dengan skor tertinggi adalah mudah mendapatkan bahan baku. Sedangkan untuk kelemahan dengan skor tertinggi adalah hanya usia muda yang mengetahui pengolahan kopi dengan cara modern.

\section{Analisis Lingkungan Eksternal}

Pada faktor eksternal terdapat beberapa aspek yaitu sosial budaya dan demografi, hukum, ekonomi, teknologi, pesaing. Didalam faktor eksternal terdapat peluang dan juga ancaman (David 2002). Pada peluang terdapat di aspek sosial budaya dan demografi yaitu adanya budaya anak muda pada jaman sekarang yang jika menongkrong atau berkumpul, bergadang minuman yang diminati adalah kopi, sehingga kopi ini sedang banyak diminati oleh masyarakat. Untuk hukum ini sendiri KUB merupakan program pemerintah yang ada di dalam undang-undang dan tujuannya adalah membantu mensejahterakan masyarakat sehingga ini merupakan peluang untuk KUB Mandiri Sejahtera karena pasti usahanya sudah di dukung oleh pemerintah. Usaha kopi milik KUB Mandiri ini juga memiliki P-IRT, sertifikat organik dan juga sertifikat halal, sehingga hal ini menjadikan peluang untuk produknya lebih mendapatkan keperacyaan dan keunggulan di mata konsumen. Secara ekonomi adalah banyaknya penawarn CSR 
dari perbankan atau BUMN dengan bunga yang rendah sehingga ini menjadi peluang untuk mendapatkan modal usaha kopi ini. Selain itu pasar yang dimiliki oleh KUB Mandiri Sejahtera masih dapat diperluas lagi, mengingat wilayah Indonesia ini luas dan belum semua wilayah mengenal kopi ngrancah. Dari segi teknologi peluang untuk saran promosi tersedia secara murah dan banyak untuk era modern pada saat ini, masih banyak ecommerce dan aplikasi-aplikasi untuk membantu promosi. Dari peluang yang di dapatkan di evaluasi faktor eksternal didapatkan skor sebesar 2,19.

Ancaman yang dimiliki oleh pihak KUB Mandiri Sejahtera didapatkan dari aspek pesaing serat sosial dan demografi. Pada aspek pesaing memiliki ancaman dikarenakan peluang yang besar akan usaha kopi ini menjadikan jumlah usaha yang sejenis ini pun semakin banyak. Adanya produk sibstitusi atau produk pengganti minuman lain selain kopi terdapat produk minuman yang lain seperti teh, susu. Kemudian kopi ini masing-masing produk memiliki ciri khas rasa berbeda-beda, dan penikmat kopi juga memiliki selera rasa konsumen yang berbeda-beda juga, perubahan selera konsumen ini lah yang menjadi salah satu ancaman. Dengan banyaknya persaingan usaha sejenis membuat adanya persaingan harga guna untuk mendapatkan ketertarikan konsumen. Secara sosisal budaya dan demografi adalah ancaman perubahan cuaca yang menyebabkan pengaruh akan produksi kopi tersebut. Dari ancaman untuk evaluasi faktor eksternal memiliki skor sebesar 0,4. Sehingga total skor dari evaluasi faktor eksternal sebesar 2,59 
Pratiwi et.al. Analisis Kelayakan dan Strategi Pengembangan Usaha Kopi di KUB..

Tabel 2. Hasil Matriks EFE (Evaluasi Faktor Eksternal) KUB Mandiri Sejahtera Tahun 2020

\begin{tabular}{|c|c|c|c|}
\hline & Bobot (a) & Rating (b) & $\begin{array}{c}\text { Skor } \\
(\mathbf{a} \times \mathbf{x})\end{array}$ \\
\hline \multicolumn{4}{|l|}{ Peluang } \\
\hline Produk kopi sedang banyak diminati & 0,08 & 3,12 & 0,25 \\
\hline KUB merupakan program pemerintah & 0,08 & 3 & 0,24 \\
\hline Produk bersertifikat organik & 0,08 & 3,37 & 0,26 \\
\hline Produk bersertifikat halal & 0,11 & 3,62 & 0,39 \\
\hline KUB Mandiri Sejahtera memiliki P-IRT & 0,11 & 3,5 & 0,38 \\
\hline $\begin{array}{l}\text { Adanya penawaran program CSR oleh } \\
\text { Kelompok-Kelompok perbankan dan } \\
\text { BUMN bagi pengembangan IKM dengan } \\
\text { bunga sangat rendah }\end{array}$ & 0,08 & 3,37 & 0,26 \\
\hline $\begin{array}{l}\text { Pangsa pasar masih luas (masih banyak } \\
\text { wilayah yang dapat dijangkau) }\end{array}$ & 0,11 & 3,75 & 0,41 \\
\hline Sarana promosi yang tersedia & 0,08 & 3,37 & 0,26 \\
\hline Jumlah & $\mathbf{0 , 7 4}$ & 27,12 & 2,19 \\
\hline \multicolumn{4}{|l|}{ Ancaman } \\
\hline Jumlah usaha sejenis semakin meningkat & 0,06 & 1,375 & 0,08 \\
\hline Adanya produk substitusi & 0,06 & 1,625 & 0,09 \\
\hline Perubahan selera konsumen & 0,03 & 1,875 & 0,05 \\
\hline Persaingan harga yang sejenis & 0,06 & 2,375 & 0,14 \\
\hline Perubahan cuaca mempengaruhi produksi & 0,03 & 1,5 & 0,04 \\
\hline Jumlah & 0,26 & 8,75 & 0,4 \\
\hline Total & 1,00 & 35,87 & 2,59 \\
\hline
\end{tabular}

Sumber : Analisis data primer 2020

Berdasarkan matriks EFE, total skor sebesar 2,59 yang berarti lebih besar dari 2,5. Hal tersebut menunjukkan bahwa usaha kopi di KUB Mandiri Sejahtera dalam menghadapi dinamika lingkungan eksternal posisi perusahaan relatif kuat (David, 2002). Skor tertinggi untuk peluang adalah pangsa pasar yang dimiliki masih luas. Sedangkan untuk ancaman skor tertinggi adalah persaingan harga sejenis.

\section{Matriks IE (Internal Eksternal)}

Berdasarkan hasil skor matriks EFI (Evaluasi Faktor Internal) dan matriks EFE (Evaluasi Faktor Eksternal) maka di dapatkan matriks IE sebagai berikut : 
Jurnal Dinamika Sosisal Ekonomi, 21 (2) : 190-204

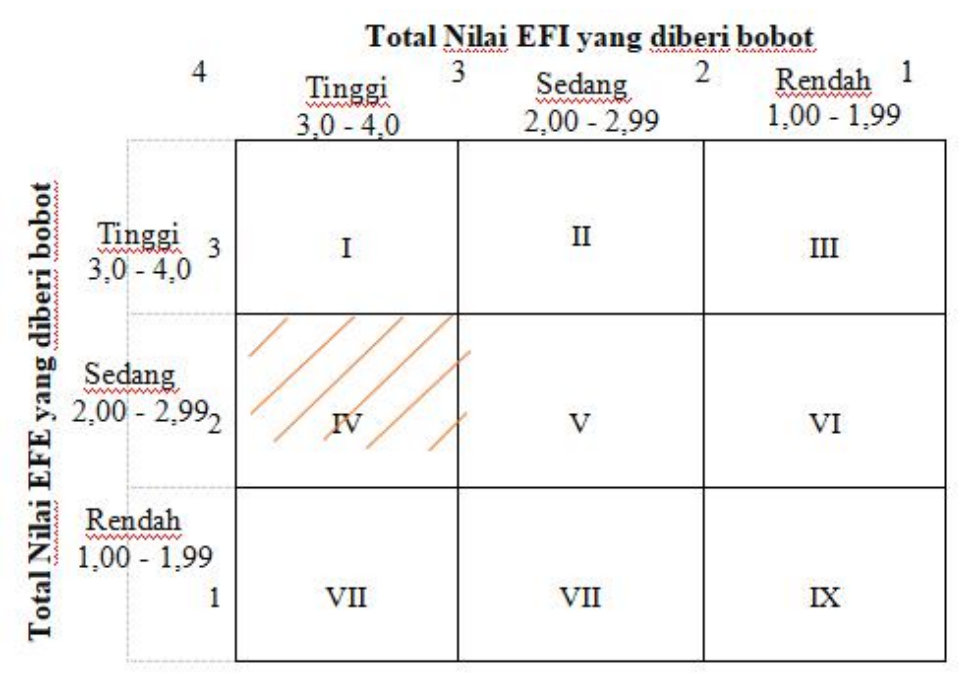

Gambar 1. Matriks IE

Berdasarkan hasil dari nilai EFE yang nilainya sebesar 3,55 dan EFI dengan nilai 2,59 yang kemudian dicocokan dengan matriks IE yang ada, maka hasil dari pemetaan tersebut usaha kopi KUB Mandiri Sejahtera terletak pada sel IV. Peta kekuatan ini meletakkan usaha kopi KUB Mandiri Sejahtera berada tumbuh dan bina. Olehkarena itu, strategi yang dilakukan apabila usaha berada pada sel IV yaitu dengan strategi intensif dengan strategi pengembangan pasar, dan strategi pengembangan produk.

\section{Matriks SWOT (strenght, weakness, opportunity, threet)}

Analisis SWOT Analisis SWOT adalah identifikasi berbagai faktor secara sistematis untuk merumuskan strategi perusahaan (Afridal, 2017) .Matriks ini digunakan untuk melakukan penentuan alternatif strategi secara logika dengan melihat kekuatan, kelemahan, peluang, dan juga ancaman.. Proses pengambilan keputusan strategis selalu berkaitan dengan pengembangan misi, tujuan, strategis, dan kebijakan organisasi. Dengan demikian perencana strategis (strategic planner) harus menganalisis faktor-faktor strategis organisasi (kekuatan, kelemahan, peluang dan ancaman) dalam kondisi yang ada saat ini (Ariani et all, 2017). Matriks SWOT merupakan matching tools untuk membantu para manajer mengembangkan empat tipe strategi, yaitu SO, WO, ST, dan WT (Lainnatussifa et all, 2018). Yaitu strategi SO (strenght opportunity) dengan menggunakan kekuatan dan memanfaatkan peluang, strategi WO (weakness opportunity) yaitu dengan memenimalkan kelemahan dengan memanfaatkan peluang, kemudian strategi ST (strenght threet) yaitu menggunakan kekuatan dengan mencegah 
Pratiwi et.al. Analisis Kelayakan dan Strategi Pengembangan Usaha Kopi di KUB..

ancaman, serta strategi terakhir adalah strategi WT (weakness threet) yaitu meminilkan kelemahan dan mencegah ancaman (Rangkuti,2001). Berikut merupakan matriks SWOT

Tabel 3 Hasil analisis SWOT (strenght, weakness, opportunity, threet)

\begin{tabular}{|c|c|c|}
\hline & $\begin{array}{l}\text { Kekuatan (Strenght) } \\
\text { Harga produk terjangkau } \\
\text { Produk kopi organik } \\
\text { Kualitas produk baik } \\
\text { Memiliki produk yang } \\
\text { khas } \\
\text { Mudah mendapat bahan } \\
\text { baku } \\
\text { Produksi yang } \\
\text { berkelanjutan } \\
\text { Bahan baku kopi organik }\end{array}$ & $\begin{array}{l}\text { Kelemahan (Weakness) } \\
\text { Sistem pembukuan masih } \\
\text { sederhana } \\
\text { Teknologi peralatan yang } \\
\text { asih kurang } \\
\text { Memiliki keterbatasan } \\
\text { modal } \\
\text { Hanya beberapa kalangan } \\
\text { muda yang menguasai } \\
\text { pengetahuan pengolahan } \\
\text { kopi secara modern }\end{array}$ \\
\hline $\begin{array}{l}\text { Peluang (Opportunity) } \\
\text { Produk kopi sedang } \\
\text { banyak diminati } \\
\text { KUB merupakan } \\
\text { program pemerintah } \\
\text { Produk bersertifikat } \\
\text { organik } \\
\text { Produk bersertifikat } \\
\text { halal } \\
\text { KUB mandiri sejahtera } \\
\text { memiliki P-IRT } \\
\text { Adanya penawaran } \\
\text { program CSR oleh } \\
\text { kelompok perbankan } \\
\text { dan BUMN bagi } \\
\text { pengembangan IKM } \\
\text { dengan bunga rendah }\end{array}$ & \begin{tabular}{l}
\multicolumn{1}{c}{ SO } \\
Mempertahankan kualitas \\
produk yang sudah ada \\
(S2,S3,S4,S8,O3,O4,O5) \\
Bekerja sama dengan para \\
petani untuk menjadi \\
pemasok bahan baku \\
$(\mathrm{S} 5, \mathrm{~S} 6, \mathrm{~S} 7, \mathrm{O} 2)$ \\
Meperluas wilayah \\
penjualan $(\mathrm{S} 1, \mathrm{~S} 4, \mathrm{O} 1, \mathrm{O} 2)$,
\end{tabular} & \begin{tabular}{l}
\multicolumn{1}{c}{ WO } \\
Meningkatkan kualitas SDM \\
yang ada di KUB Mandiri \\
Sejahtera (W4,O2) \\
Menambah penggunaan \\
teknologi (W1,W2,O2,O5)
\end{tabular} \\
\hline $\begin{array}{l}\text { Ancaman (Threet) } \\
\text { Jumlah usaha sejenis } \\
\text { semakin meningkat } \\
\text { Adanya produk substitusi } \\
\text { Perubahan selera } \\
\text { konsumen } \\
\text { Persaingan harga yang } \\
\text { sejenis } \\
\text { Perubahan cuaca } \\
\text { mempengaruhi produksi } \\
\text { kopi }\end{array}$ & \begin{tabular}{l}
\multicolumn{1}{c}{ ST } \\
Melakukan inovasi \\
produk \\
$(\mathrm{S} 2, \mathrm{~S} 3, \mathrm{~S} 4, \mathrm{~S} 5, \mathrm{~T} 1, \mathrm{~T} 2, \mathrm{~T} 3$, \\
$\mathrm{T} 4)$
\end{tabular} & \begin{tabular}{l}
\multicolumn{1}{c}{ WT } \\
Memberikan penambahan \\
edukasi untuk para \\
pengurus guna untuk \\
meningkatkan usaha \\
$(\mathrm{W} 1, \mathrm{~W} 4, \mathrm{~T} 2, \mathrm{~T} 3)$
\end{tabular} \\
\hline
\end{tabular}


Jurnal Dinamika Sosisal Ekonomi, 21 (2) : 190-204

Berdasarkan hasil matriks SWOT tersebut terbagi menjadi strategi SO,WO,ST,dan WT. Masing-masing strategi memiliki alternatif strategi. Untuk menentukan strategi mana yang digunakan maka terdapat analisis SWOT sebagai berikut :

Tabel 4. Perhitungan Strategi SO, WO,ST,WT

\begin{tabular}{lll}
\hline & Kekuatan & Kelemahan \\
\hline Peluang & $\mathrm{SO}=($ skor rata-rata kekuatan + & $\mathrm{WO}=($ skor rata-rata kelemahan + \\
& peluang $) / 2$ & peluang $) / 2$ \\
& $\mathrm{SO}=(0,41+0,27) / 2=0,34$ & $\mathrm{WO}=(0,07+0,27) / 2=0,17$ \\
Ancaman & $\mathrm{ST}=($ skor rata-rata kekuatan + & $\mathrm{WT}=($ skor rata-rata kelemahan + \\
& ancaman $) / 2$ & ancaman $) / 2$ \\
& $\mathrm{ST}=(0,41+0,08 / 2=0,24$ & $\mathrm{SW}=(0,07+0,08) / 2=0,07$ \\
\hline
\end{tabular}

Sumber : Analisis data primer 2020

Berdasarkan hasil analisis SWOT didapat hasil rata-rata SO adalah 0,34, rata-rata WO adalah 0,17, rata-rata ST adalah 0,24, dan rata-rata WT adalah 0,07. Sehingga skor tertinggi adalah SO dan strategi yang digunakan adalah strategi didalam SO.

\section{Matriks QSPM (Quantitative Strategic Planning}

QSPM digunakan untuk mengevaluasi strategi secara obyektif berdasarkan faktor-faktor sukses utama internal-eksternal yang telah diidentifikasi pada tahap sebelumnya. Teknik ini secara objektif mengindikasikan alternatif strategi mana yang terbaik. QSPM menggunakan input dari tahap pertama dan pencocokan dari tahap kedua untuk menentukan secara objektif diantara alternatif strategi. Berikut matriks QSPM :

Tabel 5 Hasil Matriks QSPM KUB Mandiri Sejahtera 2020

\begin{tabular}{|c|c|c|c|c|c|}
\hline \multirow[t]{2}{*}{ Uraian } & \multirow{3}{*}{ Bobot } & \multicolumn{4}{|c|}{ Alternatif Strategi } \\
\hline & & \multicolumn{2}{|c|}{$\begin{array}{c}\text { Pengembangan } \\
\text { Pasar }\end{array}$} & \multicolumn{2}{|c|}{$\begin{array}{l}\text { Pengembangan } \\
\text { Produk }\end{array}$} \\
\hline Kekuatan (Strenghts) & & $\mathrm{AS}$ & TAS & $\mathrm{AS}$ & TAS \\
\hline Harga produk kopi terjangkau & 0,12 & 4 & 0,48 & 4 & 0,48 \\
\hline Produk kopi organik & 0,09 & 4 & 0,36 & 4 & 0,36 \\
\hline Kualitas produk baik & 0,12 & 4 & 0,48 & 4 & 0,48 \\
\hline Memiliki produk yang khas & 0,12 & 4 & 0,48 & 4 & 0,48 \\
\hline
\end{tabular}


Pratiwi et.al. Analisis Kelayakan dan Strategi Pengembangan Usaha Kopi di KUB..

Tabel 5 Lanjutan Hasil Matriks QSPM KUB Mandiri Sejahtera 2020

\begin{tabular}{|c|c|c|c|c|c|}
\hline \multirow[t]{2}{*}{ Uraian } & \multirow[b]{2}{*}{ Bobot } & \multicolumn{4}{|c|}{ Alternatif Strategi } \\
\hline & & \multicolumn{2}{|c|}{$\begin{array}{l}\text { Pengembangan } \\
\text { Pasar }\end{array}$} & \multicolumn{2}{|c|}{$\begin{array}{l}\text { Pengembangan } \\
\text { Produk }\end{array}$} \\
\hline $\begin{array}{l}\text { Mudah mendapatkan bahan } \\
\text { baku }\end{array}$ & 0,12 & 4 & 0,48 & 3 & 0,36 \\
\hline Produksi yang berkelanjutan & 0,09 & 4 & 0,36 & 3 & 0,27 \\
\hline $\begin{array}{l}\text { Bahan baku merupakan kopi } \\
\text { organik }\end{array}$ & 0,09 & 4 & 0,36 & 3 & 0,27 \\
\hline \multicolumn{6}{|l|}{ Kelemahan (weakness) } \\
\hline $\begin{array}{l}\text { Sistem pembukuan masih } \\
\text { sederhana }\end{array}$ & 0,06 & 3 & 0,18 & 3 & 0,18 \\
\hline $\begin{array}{l}\text { Teknologi peralatan yang } \\
\text { masih kurang }\end{array}$ & 0,03 & 3 & 0,09 & 3 & 0,09 \\
\hline Memiliki keterbatasan modal & 0,03 & 4 & 0,12 & 3 & 0,09 \\
\hline $\begin{array}{l}\text { Hanya beberapa anggota } \\
\text { kelompok dari kalangan muda } \\
\text { yang menguasai pengetahuan } \\
\text { pengolahan kopi secara } \\
\text { modern } \\
\text { Faktor Eksternal Kunci }\end{array}$ & 0,06 & 3 & 0,18 & 2 & 0,12 \\
\hline \multicolumn{6}{|l|}{ Peluang (oppertunities) } \\
\hline $\begin{array}{l}\text { Produk kopi sedang banyak } \\
\text { diminati }\end{array}$ & 0,08 & 4 & 0,32 & 4 & 0,32 \\
\hline $\begin{array}{l}\text { KUB merupakan program } \\
\text { pemerintah }\end{array}$ & 0,08 & 3 & 0,24 & 3 & 0,24 \\
\hline Produk bersertifikat organik & 0,08 & 4 & 0,32 & 3 & 0,24 \\
\hline Produk bersertifikat halal & 0,11 & 4 & 0,44 & 3 & 0,33 \\
\hline $\begin{array}{l}\text { KUB Mandiri Sejahtera } \\
\text { memiliki P-IRT }\end{array}$ & 0,11 & 4 & 0,44 & 3 & 0,33 \\
\hline $\begin{array}{l}\text { Adanya penawaran program } \\
\text { CSR oleh Kelompok- } \\
\text { Kelompok perbankan dan } \\
\text { BUMN bagi pengembangan } \\
\text { IKM dengan bunga sangat } \\
\text { rendah }\end{array}$ & 0,08 & 4 & 0,32 & 4 & 0,32 \\
\hline $\begin{array}{l}\text { Pangsa pasar masih luas } \\
\text { (masih banyak wilayah yang } \\
\text { dapat dijangkau) }\end{array}$ & 0,11 & 4 & 0,44 & 4 & 0,44 \\
\hline $\begin{array}{l}\text { Sarana promosi yang tersedia } \\
\text { Ancaman (threat) }\end{array}$ & 0,08 & 4 & 0,32 & 3 & 0,24 \\
\hline $\begin{array}{l}\text { Jumlah usaha sejenis semakin } \\
\text { meningkat }\end{array}$ & 0,06 & 3 & 0,18 & 4 & 0,24 \\
\hline Adanya produk substitusi & 0,06 & 4 & 0,24 & 3 & 0,18 \\
\hline
\end{tabular}


Tabel 5 Lanjutan Hasil Matriks QSPM KUB Mandiri Sejahtera 2020

\begin{tabular}{lccccc}
\hline Uraian & Bobot & \multicolumn{3}{c}{ Alternatif Strategi } \\
& & $\begin{array}{c}\text { Pengembangan } \\
\text { Pasar }\end{array}$ & $\begin{array}{c}\text { Pengembangan } \\
\text { Produk }\end{array}$ \\
\hline Perubahan selera konsumen & 0,03 & 3 & 0,09 & 4 & 0,12 \\
Persaingan harga yang sejenis & 0,06 & 3 & 0,18 & 4 & 0,24 \\
Perubahan cuaca & 0,03 & 4 & 0,12 & 3 & 0,09 \\
mempengaruhi produksi kopi & 0,03 & & $\mathbf{7 , 2 2}$ & & $\mathbf{6 , 5 1}$ \\
\hline Total & $\mathbf{1 , 0 0}$ & &
\end{tabular}

Sumber : Analisis data primer 2020

Berdasarkan hasil penilaian QSPM, maka diperoleh urutan dari nilai TAS paling tinggi hingga paling rendah. Dari urutan tersebut dapat dihasilkan strategistrategi prioritas yang dapat diimplementasikan (Mahfud, 2017). Strategi pengembangan pasar mendapatkan skor sebesar 7,22 dan strategi pengembangan produk 6,51. Berdasarkan hasil tersebut yang memiliki skor tertinggi adalah strategi pengembangan pasar. Sehingga hasil QSPM strategi yang digunakan adalah Strategi pengembangan pasar. Jika melihat berdasarkan matriks SWOT strategi yang digunakan adalah strategi SO. Dimana strategi SO ini mempunyai tiga strategi yaitu mempertahankan kualitas produk, bekerja sama dengan pemasok bahan baku, dan perluasan wilayah penjualan. Sehingga dapat disimpulkan bahwa strategi pengembangan usaha untuk usaha kopi di KUB Mandiri Sejahtera adalah strategi pengembangan pasar dengan memperluas wilayah penjualan

\section{KESIMPULAN DAN SARAN}

\section{Kesimpulan}

Strategi pengembangan usaha yang dapat dilakukan untuk usaha kopi di KUB Mandiri Sejahtera adalah melakukan pengembangan pasar dengan memperluas wilayah penjualan produk kopi KUB Mandiri Sejahtera.

\section{Saran}

KUB Mandiri Sejahtera sebaiknya memperbaiki sistem manajemen dengan pembagian tugas yang lebih jelas sehingga di dalam pelaksanaannya di dalam usaha ini agar lebih jelas dan dapat lebih berkembang. Sebaiknya KUB Mandiri 
Pratiwi et.al. Analisis Kelayakan dan Strategi Pengembangan Usaha Kopi di KUB..

Sejahtera memaksimalkan promosi melalui media online seperti dengan membuat blog atau website, memanfaatkan E-Commerce seperti tokopedia, shoppe, dan lain-lain agar produk kopi ini lebih dikenal secara luas ke seluruh wilayah Indonesia dan memudahkan dalam konsumen mendapatkan produk tersebut.

\section{DAFTAR PUSTAKA}

Afridal, Muhammad. (2017) . Strategi Pengembangan Usaha Roti Tanjong di Kecamatan Samalangka Kabupaten Bireuen. Jurnal S. Pertanian, 1 (3) : $223-233$

Alyas, Rakib Muhammad. (2017). Strategi Pengembangan Usaha Mikro,Kecil, dan Menengah dalam Penguatan Ekonomi Kerakyatan. Jurnal Sosiohumaniora 19 (2) : 114-120.

Ariani, Nur Utomo Muhammad. (2017). Kajian Strategi Pengembangan Usaha Mikro Kecil Dan Menengah (Umkm) Di Kota Tarakan. Jurnal Organisasi dan Manajemen, 13 (2) : 99 - 118.

David, Freed R. (2002). Manajemen Strategis: konsep alih bahasa Alexander Sindoro. Jakarta : Prenhallindo

Effendi Usman, Astuti Retno, Melati Diana Candra. (2017). Strategi Pengembangan Usaha Cokelat Menggunakan Quantitative Strategic Planning Matrix (QSPM) dan Multi Attribute Utility Theory (MAUT) di Kampung Coklat, Blitar. Jurnal Teknologi dan Manajemen Agroindustri, $6(1): 31-40$.

Juwono, Onny. (2011). Analisis Manajemen Strategi Perusahaan Waralaba. Penelitian Fakultas Ekonomi. Universitas Budiluhur

Lainnatussifa, Muhib Acep, Soeyatno Rahmah Faradita. (2018). Strategi Pengembangan Usaha Cake Buah Naga Sebagai Ikon Oleh-Oleh Asli Batam. Jurnal Agribisnis, 12 (1) : 32-41.

Mahfud Tuatul, Mulyani Yogiana. (2017). Aplikasi Metode QSPM(Quantitative Strategic Planning Matrix) (Studi Kasus: Strategi Peningkatan Mutu Lulusan Program Studi Tata Boga). Jurnal Sosial Humaniora dan Pendidika,. 1 (1). : 66-76

Nazir, Moh. (1983) . Metodologi Penelitian. Jakarta: Ghalia Indonesia

Pertiwi. (2018) . Kopi Dari Desa Ngrancah Memiliki Karakter Rasa Asam Legit Ini Sebabnya. https://food.detik.com/berita-boga. diakses 18 Oktober 2019.

Rangkuti, Freddy. (2001) . Analisis SWOT Teknik Membedah Kasus Bisnis. Jakarta: Gramedia Pustaka Utama

Rosyadi, Imron. (2013) . Strategi Pengembangan Usaha Mikro Milik Mahasiswa. Jurnal Manajemen dan Bisnis. 17 (2) : 111-122.

Susanto, Irwan. (2019) . Kelompok Usaha Bersama. https://www.kemsos.go.id/kube. diakses pada 18 Oktober 2019 